\title{
Urgences
}

\section{Robert Maltais, Journal d'un journaliste en grève, L'Isle-Verte, La Maison de la page qui tourne, 1981, 104 p.}

\section{Lise Lessard}

Numéro 3, 4e trimestre 1981

URI : https://id.erudit.org/iderudit/025050ar

DOI : https://doi.org/10.7202/025050ar

Aller au sommaire du numéro

Éditeur(s)

Urgences

ISSN

0226-9554 (imprimé)

1927-3924 (numérique)

Découvrir la revue

Citer ce compte rendu

Lessard, L. (1981). Compte rendu de [Robert Maltais, Journal d'un journaliste en grève, L'Isle-Verte, La Maison de la page qui tourne, 1981, 104 p.] Urgences, (3), 90-92. https://doi.org/10.7202/025050ar d'utilisation que vous pouvez consulter en ligne.

https://apropos.erudit.org/fr/usagers/politique-dutilisation/ 
Chose certaine, Mario Cotté n'en est sûrement pas au tarissement de l'inspiration. Son oeuvre poétique n'a pas traversé toutes ces années pour déboucher sur une fin aussi abrupte. Considérons-la plutôt comme un relais, un tremplin sur ce que lui seul pourrait nous révéler.

Jean Cossette

COTTÉ, Mario. Fragments d'être. Sherbrooke, Éditions Cosmos, Collection "Amorces" No. 9, 1971. 64 pages.

COTTÉ, Mario. Espaces d'ombre. Sherbrooke, Naaman, Collection "Création" No. 15, 1976. 82 pages.

COTTÉ, Mario. Plénitudes. Sherbrooke. Éditions Naaman, Collection "Création" No. 98, 1981. 62 pages.

JOURNAL D'UN JOURNALISTE EN GRĖVE, Robert Maltais, 104 pages, La Maison de la page qui tourne.

Le 30 septembre 1980, se déclenchait la grève des journalistes de Radio-Canada au Québec, conflit de travail qui devait s'étendre sur de longs mois. L'un des douze journalistes de ce média canadien à Rimouski profita de son congé forcé pour tâter de la littérature, comme c'est devenu de mise depuis quelques années en pareilles circonstances.

Victime "écorchée" de cette grève, née à l'orée de I'hiver, Robert Maltais, qui en suivit le cheminement pénible, se réconforte en pensant: "Il me reste au moins un peu de papier pour écrire." (1). Ainsi, au gré des heures creuses, s'élabore le "Journal d'un journaliste en grève", publié à compte d'auteur, à la Maison de la page qui tourne.

L'avant-propos, petit hors-d'oeuvre éveillant la curiosité et le goût de partager "le menu" de ce "journaliste en proie à la littérature" (2), pose cet avertissement: ce livre " $n$ 'a rien d'une chronique exhaustive d'un arrêt de travail, pas plus qu'il ne se veut la voix d'un syndicat en mal de publicité, bien qu'il renferme quel- 
ques portraits d'une grève. Bien au-delà, ce livre est un cours d'eau sinueux où s'ébat la vie..."

Si, naïvement charmé de l'entrée en matière invitante, on plonge avec enthousiasme dans la matière en question, on risque dès les premières pages de donner de la tête sur de traîtres lieux communs: "L'argent ce nerf de la guerre nous fait en partie faux bond". (3)

“Il est presque affolant - à tout le moins navrant - de réaliser qu'une vie s'épuise à travailler sans relâche et qu'au bout il n'en reste si peu de choses..." (4)

“Il serait sans doute naïf de compter sans l'argent, sans cette monnaie dont nous sommes tous à des degrés divers, les esclaves." (5) "L'homme reste en tout état de cause son pire ennemi" $^{\prime \prime}$ (6) Et ainsi de suite...

Ces clichés, parsemant en dures épreuves les quelques cent pages, n'étouffent cependant pas tout-à-fait le désir de lire un écrit qui "comme chaque livre", du dire de l'auteur à la page 49, "même s'il ne contient qu'une seule belle page" peut s'avérer "un arbrisseau salvateur... une source fraîche qui coulera dans le tunnel sans fin du temps". (7)

On nous avait affirmé auparavant à la page 39: "Mais le métier (le journalisme) a un urgent besoin d'air frais". (8) Ce qui est vrai pour le journalisme l'est aussi hélas pour la littérature.

$\mathrm{Si}$ on ne cherche pas dans ce volume le récit d'une grève, comme le conseille judicieusement l'avant-propos, ni le journal d'un journaliste, malgré les passages se référant au métier, surtout en région; si on arrive à passer sans trop de mal sur certaines considérations hic (philosophiques, sociologiques, politiques, écologiques) plus ou moins neuves et qu'on apprécie les commentaires écourtés alors, le journal..., car ça en est un, d'un journaliste... qui en est vraiment un, en grève... qui en fut toute une, saura procurer des instants agréables, agiter des souvenirs, provoquer des réflexions et bien sûr quelques critiques. 
En terminant, je me permets de revenir à l'avant-propos (décidément!) pour retrouver ces phrases: “Écrire un livre... tient autant de la témérité que de la folie..." (9) "Mettre un livre au monde, c'est permettre à la liberté d'expression, si fondamentale, d'avoir cours". (10) Ne fut-ce que pour cela, le livre mérite d'être
(1) page 17
(2) page 9
(3) page 14
(4) page 16
(5) page 17
(7) page 49
(8) page 39
(6) page 21
(9) page 10
(10) page 10

\begin{abstract}
"A DIABLE-VENT" d'Hélène Gauthier-Chassé, Éditions QUINZE, collection Mémoires d'homme.
\end{abstract}

Comme il n'y a même pas besoin d'y croire pour les savourer, et qu'au contraire le fait même d'en douter ajoute toujours au plaisir de les lire (le rire étant une occupation si agréable!) les LÉGENDES ET CONTES POPULAIRES, que taisent de plus en plus les voix tremblotantes et joyeuses de nos grand-pères (car qui encore aujourd'hui a la chance d'en avoir un dans sa boîte à lunch ou son sac d'école?) ne sauront disparaître comme par enchantement, tant que des auteurs, amoureux de ces "vieilleries" qui font partie intégrante de Notre Histoire, partiront avec curiosité et sensibilité les cueillir comme d"“immortelles" immortelles.

Et qui plus est, tant que ces mêmes amoureux s'intéresseront aux transformations que le temps et les gens ne peuvent manquer invariablement de leur faire subir, comme étant la preuve indéniable de leur pérennité. Car, "rien ne meurt de façon simple" comme le dit elle-même Hélène Gauthier-Chassé, dans la Préface de son "légendaire" A DIABLE-VENT paru dans Mémoires d'homme, aux éditions QUINZE. Elle nous y offre, avec une joie évidente et une grande finesse, un répertoire de certaines légendes du Bas Saint-Laurent et de la Vallée de la Matapédia. S'y côtoient, comme de bien entendu, les diables, les feux follets, les poules noires, les maisons hantées, les roches enchantées, les bals du Mardi-Gras qui se terminent par des planchers brûlés et des empreintes de griffes sur des épaules blanches. (Nos bonnes vieilles légendes!!!). 